\section{DE DE GRUYTER}

OPEN

政

Germinal Isern ${ }^{10}$

Clark University
Journal of Intercultural Management

Vol. 7, No. 3, September 2015, pp. 53-67

DOI 10.1515/joim-2015-0021

\title{
Intercultural Project Management for IT: Issues and Challenges
}

\begin{abstract}
The development of Information Technology projects using Project Management Methodologies like PMP-PMI, Agile or SCRUM for software development, CPM, CCPM, RAD, XP, FDD, ITIL, JAD, LD, PRINCE2, etc.; may be a complete success or a total catastrophe, for series of reasons, events and circumstances that frequently are not related at all with the deliverables, the products being built, the IT technology involved, the level of expertise, the responsibility and professionalism of the stakeholders including the project manager, but due to intercultural factors. The PMP-PMI Model (PMBOK) describes 10 areas: Cost Management, Time Management, Scope Management, Risk Management, Quality Management, Procurement Management, Integration Management, Stakeholder Management, Human Resources Management and Communication Management. An IT project is considered successful if the customer is happy, but technically and formally if the TEAM was able to meet the triple constraint set up by time/cost/scope. This happy ending is not possible if the project manager and the team as a whole are not able to confront, attack and solve the issues associated with Human Resources Management, Stakeholder Management and specially Communication Management.

These three areas are highly influenced by Intercultural factors like language, race, age, gender, religion, sexual preferences, beliefs, habits, etc., becoming their analysis an essential task if we want to accomplish and guarantee a favorable outcome. This position paper concludes in contradiction with what is a very common believe between many technical project managers that the most important factors to take in consideration for the success of an IT project management is the careful and planned attention to the potential issues and challenges associated with the cross-cultural communication and the human
\end{abstract}

\footnotetext{
${ }^{10}$ gisern@clarku.edu
} 
resources implicated in the projects. This paper will describe the cultural dimensions, issues and challenges associated with Intercultural Project Management for IT.

Key words: Project Management for IT, Project Management, Intercultural Communication, Intercultural Management, Intercultural Information Technology Management.

\section{Introduction}

During the last 15 years half of the off-shoring and outsourcing phenomenon has specially focused on Global Software Development. The success of the Indian companies, the appearance of new players like Brazil, China, and particularly programmers coming from Eastern European and from Latin-American countries in conjunction with the robustness exhibited by software companies in Israel, has made the Project Management Business for Software Development the most important task in the Information Technology Environment right now.

Cultural differences in International Project Management are very important. An international project manager who works aboard has to take these cultural differences in religion, language, traditions, ethics, background, etc. in consideration if he or she wants to succeed in his (her) role as a leader of the team. Global Project Teams are confronted with the task of balancing Western Project Management practice with local business customs, cultural dimension conflicts, cross-cultural communications challenges, human resources issues and heterogeneous legal frameworks in order to be able to deliver high quality results. Bill Young past president of the AIPM (Australian Institute of Project Management), who lives and works in China declare that " $50 \%$ of joint-venture project between Western companies and Chinese companies fail" [Young 2013].

Understanding cultural differences is one key to the success. China is one of the biggest markets today and a great place to experiment and analyze these issues and challenges [Wong 2008a]. Cultural differences are clearly perceived by a non-local project manager working in international developments to be biggest challenge in China [Saee 2013]. Additional unwanted situations related to project management in China reflect poor quality, workers hiding problems from management; weak team ethic, corner-cutting, poor technical communication and inadequate involvement by middle management [Wong 2008].

Project managers are usually very experienced professionals with great ability to plan and organize tasks and people. Soft skills, leadership, organization are essential attributes of a good project manager, the PMI-PMP PMBOK [PMI 2013] describe the core areas involved in the right management of a project and clearly identify Communication, Human Resources and Stake Holders Management as core knowledge areas, but this new dimension of Intercultural Project Development makes the cultural dimensions to be identified as a critical influence on the potential 
failure or success of IT Project Management process specially for Global Software Development, IT Outsourcing, Off-shore Project Development and Multicultural Project Development.

\section{Cultural Dimensions}

Cultural dimensions are identified factors of great influence on the expected success of IT systems. These aspects must also be contemplated by institutions which projects are deploy off-shore or outsource to international companies or projects developed by teams integrated with staff coming from all around the world, with different social backgrounds, with different perspectives, cultures and/ or traditions.

Hofstede's cultural dimension's research is the first reference about culture within Information Systems literature [McCoy 2003, Isern 2014]. Ali and Alshawi [Ali 2005] described a comprehensive cultural dimensions framework, based on Hofstede's cultural dimensions. Dozens of papers have been published describing the world as a melting pot of races, religions, traditions, etc. in a nutshell cultures; giving a set of general concepts and ideas, however, the typologies of culture do have inherent weaknesses since they do not show a clear reflection of the diversity of values and attitudes that may exist in a country or even in a region of a country, nor do they give an explanation of how cultures have developed along the time. This paper wants to raise the level of awareness about the limitations that need to be considered, when analyzing the impact of culture on the Information Technology Project Management[Skok and Legge 2001].

This paper will try to describe the intercultural factors involved and the issues and challenges that those factors create in the Project Management process.

According to experts in the field of intercultural communication, some of those factors [Isern 2014] include:

- The Cultural Identity Factor;

- The Racial Identity Factor;

- The Ethnic Identity Factor;

- The Gender Role Identity Factor;

- The Individual Identity Factor;

- The Social Class Identity Factor;

- The Age Identity Factor;

- The Roles Identity Factor.

Let's first describe Hofstede's work and other author's to later summarize some results and outline some final remarks and recommendations.

\section{Culture, cultural theories and intercultural factors}

Culture is the integrated pattern of knowledge, belief, and behavior that depends upon the capacity for learning and transmitting knowledge to succeeding generations. 
Culture is the learned values and behaviors shared by a group of people and play a vital role in how a person performs his or her work based on individual patterns of thinking, feeling, and acting. Culture has visible attributes like dining, clothing, religious rituals, architectures, or sports while invisible attributes comprise of orientations to environment, time, communication, space, power, individualism, competitiveness, structure, and thinking. Several theories have been proposed to categorize cultural differences. As the primary source of intercultural factors, we used the works of E.T. Hall [Hall 1976], G. Hofstede [Hofstede 1980, 1997, Fiske [Fiske 1991, 1992] and F. Trompenaars \& Charles Hampden-Turner [Trompenaars 1997].

\section{Hofstede's Cultural Dimensions}

- Power Distance (PDI),

- Individualism/Collectivism (IDV),

- Uncertainty Avoidance (UAI),

- Masculinity/Femininity (MAS),

- Short-term or Long-term Orientation (LTO).

These dimensions give insight to different national cultures.

\section{E. T. Hall's Cultural Facto}

E.T. Hall, based on anthropological analyses identified key cultural factors. These are classified into High Context and Low Context based on time and space. Hall also looked at the way cultures handle time mono-chronic cultures versus poly-chronic cultures.

\section{Trompenaars \& Hampden-Turner Dimensions}

- Universalism vs. Particularism;

- Individualism vs. Communitarianism;

- Neutral vs. Emotional;

- Specific vs. Diffuse;

- Achievement vs. Ascription (attitude toward titles, degrees...);

- Sequential vs. Synchronic cultures;

- Internal vs. External control.

Fiske forms of socialite

- CS: communal sharing: do people treat all members of a category as equivalent.

- AR: authority ranking: do people attend to their positions in a linear ordering.

- EM - equality matching: how people keep track of the imbalances among them.

- MP: market pricing, how people orient to ratio values.

Hofstede's cultural dimensions help project managers and team leaders to recognize individual and group behaviors in different countries. E.T. Hall's adds 
the dimensions based in context concept of time and space. Trompenaars and Hampden- Turner have a contradict Hofstede's cultural dimensions approach because they view culture as process and propose that ,culture is the way in which a group of people solve problems and reconcile dilemmas'. Hofstede analyses the variables of national cultures, whereas Trompenaars and Hampden-Turner are involved in the processes of cultural creation. Many other researchers such as Philippe d'Iribarne [d'Iribarne 2009] have the same approach as Hall but with an ethnographic method for sense making. Vaara [Vaara 2000] has broadened these cultural studies with an epistemological approach that states culture and cultural differences exist only when people become aware of it in their social interactions.

Stahl [Stahl 2003] differentiated two dimensions of culture. The first one states that different culture are fundamentally and possibly irreconcilably different, whereas the second one states that all cultures share some universal attributes.

Stahl has concluded that, despite obvious difference in cultures, there are similarities that are based on human nature, and we believe that those one could be used to reach out to the stakeholders and vaporize the conflicts. Ali \& Alshawi [Ali 2004] outline three types of culture. First, there is the culture that a society shares (national culture), a set of core values that shape the behavior of individuals as well as the whole society. Second, there is the culture on a smaller level, namely organizational culture Adler [Adler 1997] and Bagchi and Cerveny [Bagchi 2003]. Third, there is the individual level of culture Dorfman and Howell [Dorfman 1988] that describes the effects of national culture on individual behavior.

\section{Proposed factors to be included in the cultural dimensions and a critique of Hofstede framework}

Despite the common use given to Hofstede cultural dimensions research, his work can be seen as only one way of looking to culture within the Information Systems and Technology discipline McCoy [McCoy 2003]; Ali and Alshawi [Ali 2004a, 2005]. We must make a deeper analysis of the impact of the culture dimensions on the Project Management; Walsham [Walsham 2002] stated that the Structure Analysis Theory of Giddens could be used to analyze the similitude and difference in a variety of cultural sub-groups and even individuals.

\section{Culture, Structures Theory and Information Systems}

The theory of Giddings as described by Walsham, has been very influential in the social sciences, receiving also considerable attention in the IS field. We propose to use this theory of Giddings plus the models of Hofstede, Fiske, Trompenaars and Hampden-Turner, E.T. Hall, Philippe d'Iribarne, Vaara plus the contribution of Adler, Ali and Alshawi with the summary of Walsham to build a more formal and general strategy to review cross cultural and intercultural factors in Project 
Management. We believe that are important connections between the cultural dimensions of Masculinity and Individualism with the tendency that some Project Managers have to adopt a Competitive style of conflict management. We also share with Mohammed and White that Uncertainty Avoidance could be correlated with the propensity for Project Managers to follow an Avoiding approach to conflict management [Mohammed 2008]. More relationships are found between Hofstede's cultural dimensions and conflict management styles in Project Managers but their meaning requires further study, that way we would like to describe the PMP-PMI model to identify the phases, processes and cores areas mainly involved with the cultural dimensions issues and how that imposes challenges for IT Project Mangers I order to propose some recommendations.

\section{The PMP-PMI PMBOK model}

Project Management Body of Knowledge (PMBOK) describes the theory that encompasses the practice of project management. These theories are dynamic, integrative processes that are in constant evolution as practice grows and changes. The entire PMBOK incorporates scientifically sound theories in project management along with novel theories and processes that are being tested and proven. The PMBOK includes written frameworks of practice as well as informal and unwritten knowledge. Project management is itself a complete science and as a discipline is useful in a wide variety of domains such as software engineering, construction, architecture, and automotive utilizations. There are five process groups (or steps) and nine knowledge areas is project management (see Figure 2 and Figure 3). Each of the nine knowledge areas in itself contains the five process groups. Each knowledge area needs all five process groups in order to function. Every process in a project management plan becomes interrelated to at least one knowledge area and one process group. The use of the PMBOK and the number of certified PMI Project Managers is been drastically growing since mid-90, but lately with the boom of international outsource off-shore software development projects, the number has grown even more (see Figure 1). 
Figure 1. Number of Certified PMP-PMI Professionals

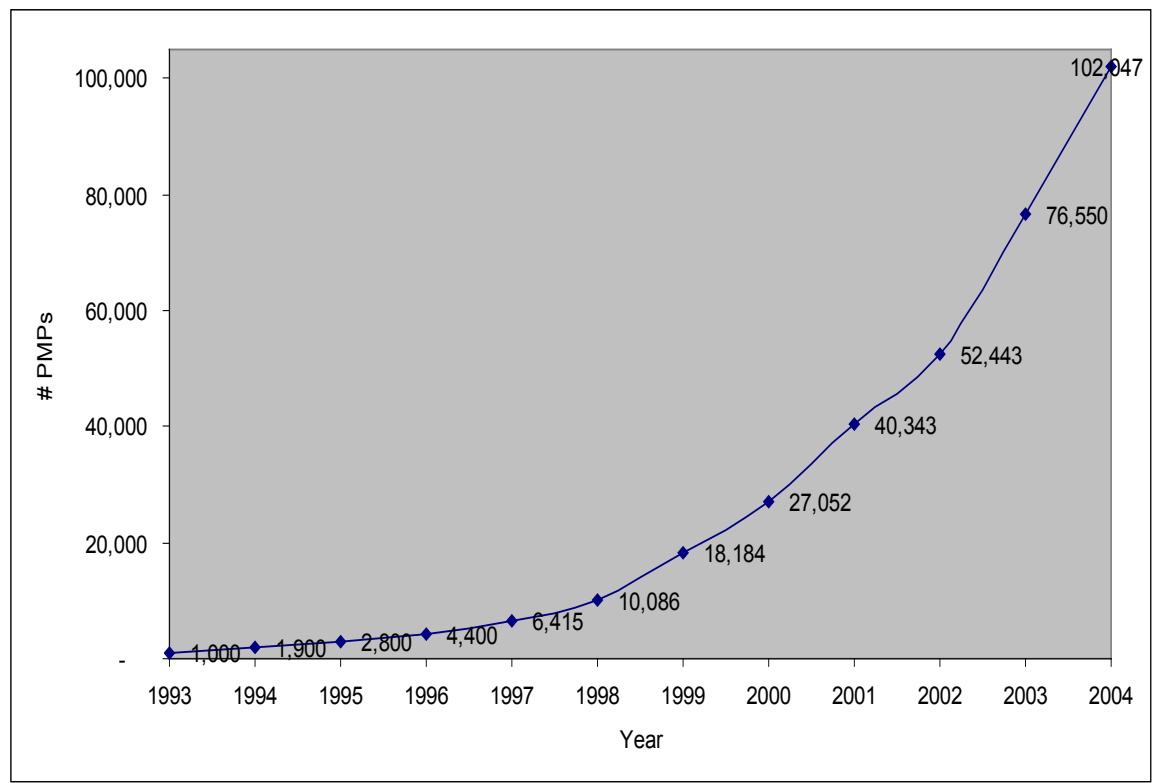

Source: PMI 2013.

The PMBOK describes an internationally recognized approach towards project management [PMI 2013]. It can be applied to all types of projects, such as engineering, construction and software. The PMBOK divides the knowledge into Project Management Knowledge Areas, an approach that considers work as if it were being accomplished by processes.

The ten areas are:

1. Project Stakeholder Management;

2. Project Risk Management;

3. Project Integration Management;

4. Project Scope Management;

5. Project Time Management;

6. Project Cost Management;

7. Project Quality Management;

8. Project Human Resource Management;

9. Project Communications Management;

10.Project Procurement Management. 
Figure 2. General Description of the Framework of the PMBOK PMI

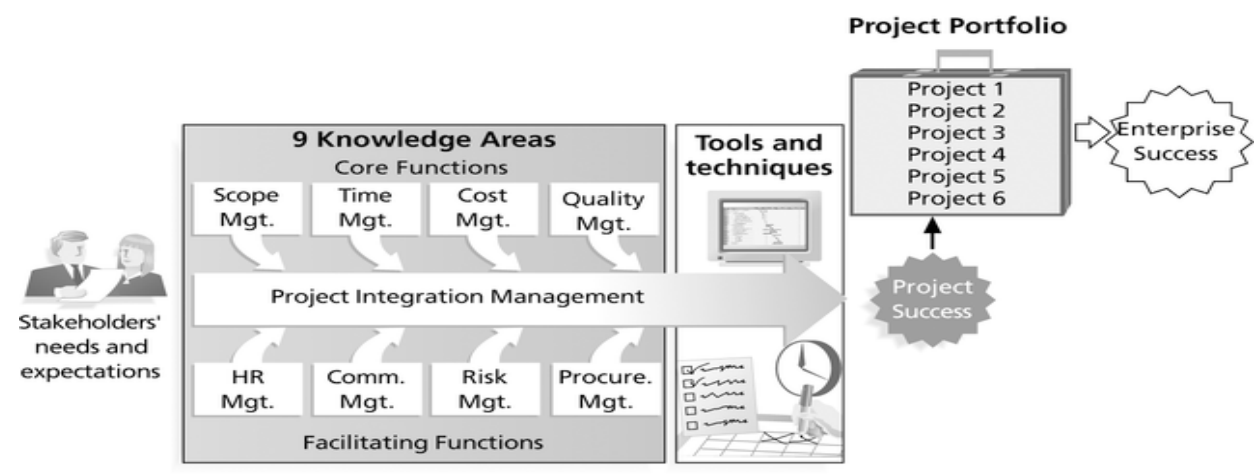

Figure 1-2. Project Management Framework

Source: PMI 2013.

It is expected that various processes will overlap with others during the phases of a project, the processes may also need to interact. Processes have certain common features:

- they have an Input, including plans and designs,

- they include Tools and Techniques, applied to the above mentioned inputs,

- and they include Outputs. These outputs include the goal of the project, such as the product, or documentation.

The concept of the PMBOK's Project Management Knowledge Areas suggests that there are only five process groups. These include:

- Initiating - deciding to perform the project,

- Planning - deciding how to run the project,

- Executing - doing the acts that comprise the project,

- Controlling and Monitoring - deciding further details about the project and measuring how the acts that comprise the project compare with the planning, and

- Closing - finishing the project, delivering and paying (See Figure 2 and Figure 3). In order to create an effective Project Management system, each of these ten knowledge areas are used, each of which may include processes from each of the five process groups. Two of the most important factor to consider is how to initiate, control and terminate every phase, how integrate the different members to every group and to every process, how to conform the teams and how to make that the 
interaction between different members is not affected by the issues related to the cultural dimensions described previously.

Each process can be defined as related to one knowledge area and one process group.

Figure 3. Knowledge areas and Processes

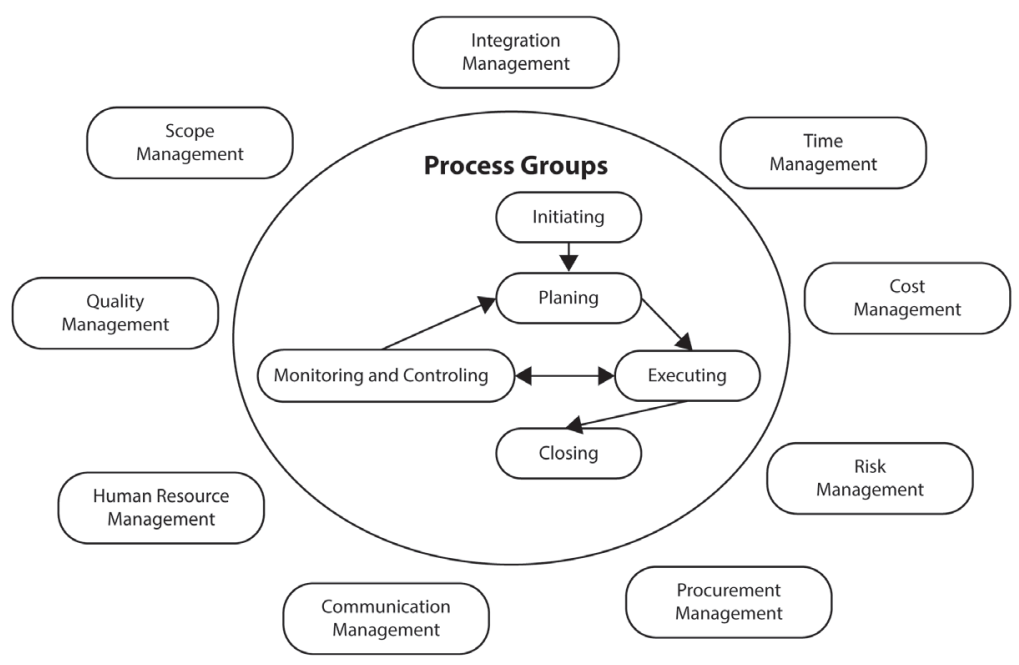

Source: PMI 2013.

All the processes and phases are very important and a lot of issues related to the cultural dimensions of project management are involved, but the 3 knowledge areas especially involved are Communication Management, Human Resources Management and Stakeholder Management.

Project Communications Management plays a key role in keeping all members of the project management team on the same page. About $90 \%$ of the time in a project is spent on communication by the project manager. Without communication among all team members and project stakeholders there can be a breakdown in processes which could have a negative impact on the final product. Among those organizations considered very effective communicators, $80 \%$ of project meet original goals, versus $52 \%$ at the not so effective counterparts, and are also more likely to deliver projects on time (71\% vs. $37 \%$ ) and within budget ( $76 \%$ vs. $48 \%$ ). (Pulse of the Profession Report). A 2012 report by PwC show similar benefits, and indicates that those organizations are more likely to stay within scope, meet quality standards and deliver intended business benefits. "A good communication process 
keeps stakeholders engaged and project team motivated" says Graham Colborne PMP manager Australia, "You need to internalize good communication strategies as part of the project culture" James Brown, Chair of the Project Management Center of Excellence;" If you want to achieve anything, you need to reach out to people...Tell them what you're doing, listen to what they need and adjust your goals as necessary" Bobbi Schroeppel, Vice President of Human Resources, Customer Care and Corporate Communications, but what if we can't reach out based in essentials differences related to the culture dimensions [PMI 2013a].

The project manager must know the communication processes involved in effective project management. First of all there should be planning to determine what information needs to be communicated to all stakeholders in the project and how. Next, that information must be made readily available to the stakeholders and generated in a timely fashion, considering all the cultural dimension issues. Finally, communication with project stakeholders must be managed so that all requirements are met and issues are promptly resolved.

There are also several key components in project communication management which should be considered. Encoding or translation to bypass the cultural differences makes sure everyone understands what is said, how is said and not produces a wrong interpretation. The output of that encoding is the message which is conveyed through a medium. Interference with the message is called noise and finally, the message must be decoded to have meaning for all involved.

As it is well known communication is not an absolute finite thing. Developing an effective communication plan may be associated with the requirements of the communication itself and can be described with the famous $5 \mathrm{w}$ (what, when, why, who, where) and $1 \mathrm{H}$ (how). Environmental factors, organizational factors and mainly the cultural dimension must be included in the analysis in order to create a coherent, holistic, effective and efficient plan.

Figure 4. Project Phases

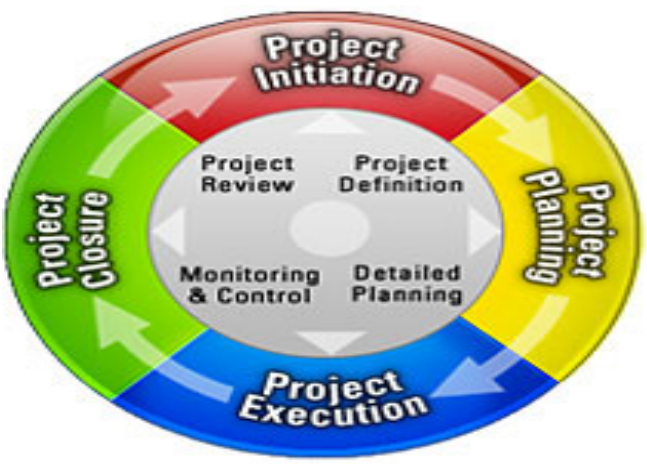

Source: PMI 2013. 
Project Human Resource Management is associated with the organization and management of the project team. The team is composed of people with specific skills, responsibilities and the most important for this work with cultural differences (languages, religions, traditions, gender, sexual preferences, etc.). All the members of the team should feel they are part of the team and understanding that their cultural differences don't make different, and each one of them is only one more member of the team despite the cultural differences, increasing as a product the loyalty and commitment to project goals and objectives. Human Resource Management in the Project-Oriented Organization it was a kind of not studied topic, even lately has promoted a lot of research. This topic in conjunction with the Project Communication Management is essential for the success of the organizations. Since Project Oriented organizations work with a different fashion, for the temporary of the projects and programs, the structure of the Human Resource should use a totally different approach [Turner 2007].

The project management team, also called the core, executive, or leadership team, is responsible for project planning, controlling, and closing and takes directives from the project team. The project management team and the project sponsor work together to secure funding, simplify scope questions, and influencing team members understanding their differences and expectations.

Project human resource management processes include human resource planning, acquiring the project team, developing the project team and managing the team. Processes are used multiple times, usually occurring at least once in a project or several times in different phases if the project is made up of many phases. In reality, processes intersect with each other and with other phases and are not as definite and concrete as illustrated here.

\section{Conclusions and Future Work}

A Project Manager must possess a broad set of skills; leadership, poise, change tolerance, proactivity, technical, management, customer relationship, and conflict management. They have to be able to use this set of skills to create an environment in which the project reach its immediate goals but also functions successfully in terms of meeting the expectations, feelings and needs of its team members. As we described, the importance of the cultural dimension of management, is especially significant in the field of Intercultural Project Management for IT. Jessen [Jessen 1992] explained that the requirements for Hofstede's cultural dimensions of individualism, power distance and uncertainty avoidance differ all along the development of a project, and therefore that cultural values have different effect during the phases of the project. Cultural patterns in project development environments, especially for Global Software Development, reflect those ones in the society. Project Managers must work in the subjacent culture of their society and of their organization and of their own specific project teams Earley and Mosakowski [Early 2004]. 
Consequently, Project Managers must be comfortable and not only comfortable if not sympathetic understanding cultural requirements of each sector of their working environment. For instance, been able to give "bad news" and to manage performance are considered key skills for a successful Project Manager. Hofstede [Hofstede 2001] described that many cultures have subtle ways of operating, Yeung and Tung, [Yeung 1996] Kohls [Kohls 1994]. For example give feedback is frequently made in some cultures (collectivist) via a third party, and not to observe such practices may result in significant damage to the project environment Slevin and Pinto [Slevin 2004]; Aycan and Kanungo [Aycan 2000].

Previous work by Prabhakar [2006, 2005a b, 2004a b] based on 153 projects in total from 28 nations demonstrate that leadership in projects is a unique challenge as opposed to the leadership of operations. During the development of a project the Manager has to continuously evaluate his or her style of leadership and adapt accordingly to the requirements of the phase (switch leadership). Further studies by Walker \& Prabhakar [Walker 2006, 2005] across 25 nations studying 111 projects identified that leading multicultural teams is an enormous challenge where the choice of project manager and his or her team is crucial. The ability of the project manager to communicate and manage human resources from multicultural environment is must.

Some recommendations are, understand the cultural differences will help you to work around them and articulate the issues. Gather the maximum information about the culture of the country beforehand. That will help you to understand: what type of people you have to deal with and how people will react to you?

Understand your own culture first and get critical about it. Three useful tips for a project manager who would like to work aboard:

1. Understand the business culture of the country. Every country has a different national culture and different ways of thinking about business.

2. Encourage project managers who work with a side partners to understand and respect these differences.

3. Be careful with stereotypes, people have different ideas and perspectives.

4. The importance of understanding languages is a must.

- For example, India has 18 national languages. The spoken languages in India are 347.

- Popular Chinese dialects - Mandarin, and Cantonese; but writing is the same.

- People talking in different languages in meeting; be respectful (is it necessary or offensive?)

- English as a Second Language (ESL) Words can mean different thing; keep it simple Idiom and slang usage How are you? How's it going? How've you been? Talk slowly and clearly (KISS); not too slowly 1 Learning other language; speaking their language? -Understand their body language 
5. Understand and respect cultural differences

- Know your clients/team and be prepared; not knowing can affect relationship

- Judging people's origin by looks Physical appearance or by their last names, for example Pakistanis are not Indian, Taiwanese are not Chinese, Korean are not Japanese

- Accent can usually tell where people are from

- Respect culture by trying their food; can be a good conversation topic

6. Understand and respect cultural differences

- Religion/Culture vs. professionalism (get help from HR) Prayer before sunset;

- People fasting (Ramadan). Not working on Sundays. Caste issue in India;

- taught to respect elders. Eye contact may be interpreted as rude.

- Siesta - a nap in the early afternoon (especially in hot countries)

- Different ways of greeting people. Namaste, Bowing, Hand shake, kissing on cheek, Rub noses, etc.

These were just a sub-set of recommendations just giving as an example.

This was a position paper just to describe potential factors involved, the set of separate theories and foundations that associate Intercultural Project Management for IT with the issues and challenges of the cultural dimensions. But we set the parameters for the future study that we hope will produce a systematic approach in order to configure and enact Intercultural Project Management for IT for Transnational, Global and multicultural target organizations being able to respect cultures, nations and groups involved and reaching the maximum effectiveness and efficiency in the interaction with the team members.

\section{Bibliography}

Adler N. (1997), International dimensions of Organizational Behavior, IT.

Ali M., Alshawi S. (2004a), A Cultural Approach to Study Customer Relationship Management (CR M) Systems, CISTM 2004, Alexandria, Egypt.

Ali M., Alshawi S. (2005), Cultural Universality Versus Particularity Within eCR M Systems: A Special Case of Information Systems, EMCIS 2005, Cairo, Egypt.

Aycan Z., Kanungo R.N. (2000), Impact of Culture on Human Resource Management Practices: A ten-country comparison, "Applied Psychology: An International Review", 49 (1), 192-221.

Bagchi K., Cerveny R. (2003), The Infuence of National Culture in Information Technology Product Adoption, AMCIS 2003, Tampa, Florida, USA.

D'Iribarne P. (2009), Conceptualizing national cultures: an anthropological perspective, http://inderscience.metapress.com/app/home/contribution.asp? referer=parent\&backto=issue, 2, 6; journal, 4, 12; linking publication results, 1:120713, 1.

Dorfman W.P., Howell J.P. (1988), Dimensions of National Culture and Effective Leadership Patterns: Hofstede Revisited, "Advances in International Comparative Management", 3, 127-150.

Early P.C., Mosakowski E. (2004), Cultural Intelligence, "Harvard Business Review”, 193-146. 
Fiske A.P. (1992), The Four Elementary Forms of Sociality: Framework for a Unified Theory of Social Relations, "Psychological Review", vol. 99, pp. 689-723.

Fiske A.P. (1991), Structures of Social Life: The Four Elementary Forms of Human Relations, New York: Free Press (Macmillan).

Giddens A. (1979), Central Problems in Social Theory, Macmillan, Basingstoke, UK.

Giddens A. (1984), The Constitution of Society, Polity, Cambridge, UK.

Hall E.T. (1976), Beyond culture, New York: Anchor Books/Doubleday.

Hofstede G. (1980), Culture's consequences, Beverly Hills, CA: Sage.

Hofstede G. (1997), Culture and organizations - Software of the mind, McGraw-Hill.

Hofstede G.J., Pedersen P.B., Hofstede G. (2002), Exploring culture; exercises, stories and synthetic cultures, Yarmouth, Maine, USA: Intercultural Press.

Isern G. (2014), Intercultural Communication and Management Factors and Their Impact to the Process of Global Software Development for Virtual and Non-Virtual Teams, "Journal of Intercultural Management", Volume 6 Number 1 January SAN: Warsaw.

Jessen S.A. (1992), The nature of project Leadership, Scandinavian University Press, Norway.

Kohls L.R. (1994), Developing Intercultural Awareness, Dallas SIL Library.

Mohammed U., White G. (2008), Culture and Conflict Management, Style of International Project Managers, "International Journal of Business and Management", vol 3, no. 5.

Phen L.S., Yuquan S. (2000), An Exploratory Study of Hofstede's Cross-Cultural Dimensions in Constructing Projects, "Management Decisions”, 20(1), 1-16.

PMI PMBOK (2013), The guide of the Project Management Body of Knowledge, Project Management Institute.

PMI (2013a), White Paper, Communication: the message is clear, Project Management Institute.

Prabhakar G.P. (2004a), A switch will induce a better Pitch, Project Management Days, Vienna, Austria.

Prabhakar G.P., Walker S.E. (2004a), Switch Leadership. Cabier de Recherché, N0.04-02. Lille Graduate School of Management, France.

Prabhakar G.P., Walker S.E. (2005a), Intercultural Team Maturity Model: Unity, Diversity, Capability, Project Perspectives, 70-73.

Russell S. (2001), Winer. Customer Relationship Management: A Framework, Research directions and the future, April.

Saee J. (2013), Project Management in China, The PM Channel, 7th January.

Sathish S., Pan S.L. et al. (2002), Customer Relationship Management (CR M) Network: A New Approach to studying CR $M$, AMCIS, Dallas, USA.

Slevin D.P., Pinto J. (2004), An overview of Behavioral Issues in Project Management [in:] P.W.G. Morris, J.K. Pinto (Eds), The Wiley Guide to Managing Projects, Hoboken, NJ: John Wiley \& Son.

Skok W., Legge M. (2001), Evaluating Enterprise Resource Planning (ERP) Systems using an Interpretive Approach. SIGCOPR2001, San Diego, USA. 
Stahl B.C. (2003), Cultural Universality versus Particularity in CMC. Proceedings of the Ninth Americas Conference on Information Systems, USA.

Trompenaars F., Hampden-Turner C. (1997), Riding the Waves of Culture, 2 Ed. New York: McGraw-Hill Trade.

Turner R., Huemann M., Keegan A. (2007), Human Resource Management in the Project-Oriented Organization, PMI Project Management Institute.

Vaara E. (2000), Constructions of Cultural Differences in Post-merger Change Processes: A Sense making Perspective on Finnish-Swedish Cases, "Management", 32, pp.81-110

Walsham G. (2002), Cross-Cultural Software Production and Use: A Structuration Analysis, MIS Quarterly, 26(4), 359-380.

Wong Z. (2008), Maximizing Project Management through Understanding Cross-Cultural Diversity, International and Cross-Cultural Projects.

Wong Z. (2008a), Human Factors in Project Management, "Journal of Product Innovation Management”, Volume 25, Issue 5, 523-524, September.

Young B. (2013), Cultural Influences in Project Management, The PM Channel, 9th January. 